\title{
Teen aesthetic surgery may eliminate bullying
} \author{
Markos Salisbury ${ }^{5}$, Robert A. Ersek ${ }^{2}$ \\ ${ }^{1}$ Cosmetic and Reconstructive Surgery, Summa Health System Akron, Akron, OH 44304, USA. \\ ${ }^{2}$ Cosmetic and Reconstructive Surgery, Personique Surgery Center, Austin, TX 78705, USA. \\ ${ }^{3}$ University of Texas, Austin, TX 78712, USA. \\ ${ }^{4}$ University of Pennsylvania Philadelphia, Pennsylvania Philadelphia, PA 19104, USA. \\ ${ }^{5}$ San Marcos University, San Marcos, TX 78660, USA.
}

Dustin Derrick', Lauren Crawford², Jim Sheridan², Randy Buckspan², Alexis Delgado ${ }^{3}$, Sebastian Gualy $^{4}$, Diana Vo $^{3}$,

Correspondence to: Dr. Robert A. Ersek, Cosmetic and Reconstructive Surgery, Personique Surgery Center, Austin, TX 78705, USA. E-mail: Bobersek@yahoo.com

How to cite this article: Derrick D, Crawford L, Sheridan J, Buckspan R, Delgado A, Gualy S, Vo D, Salisbury M, Ersek RA. Teen aesthetic surgery may eliminate bullying. Plast Aesthet Res 2017;4:178-84.

Article history:

Received: 6 Sep 2017

Accepted: 22 Sep 2017

Published: 26 Oct 2017

Key words:

Teenage surgery,

bullying,

reconstructive,

aesthetic

\section{ABSTRACT}

The media has a large influence on what constitutes modern day beauty, as it suggests to susceptible young girls and boys what makes someone beautiful. The term "beautiful" is portrayed as curvy, thin, tall, with voluptuous hair, big eyes, large breasts, round buttocks, and full lips. Very few people in society naturally appear like this, and thus many people undergo cosmetic surgery for this desired look. This article will examine the difference of opinions regarding the exact age to consider aesthetic plastic surgery. Adolescence is frequently bullied about any defect. The authors discuss some of these opinions and present three very unusual cases where early surgery has been beneficial.

\section{INTRODUCTION}

Anyone with a real or imagined physical defect such as a crooked nose, asymmetrical face, small or large breasts, or being "overweight" can be very sensitive to comments made by others. This is profoundly important to teenagers as their body changes and everyone compares each other to everyone else. The media, movies, magazines and peers, add fuel to the fire of desire for acceptance.

The development and ubiquity of "social media", has made ridicule and bullying, fast, easy and public beyond a few peers. The effects can be devastating for adolescences. Bullying may be the single most common cause for teen suicide.

Aesthetic or cosmetic surgery was a natural outgrowth of plastic reconstructive surgery that occurred following World War I and II, when medical advances such as antibiotics and sterilization made it possible for people with severe injuries to survive. They often required reconstructive surgery to create a more normal appearing face, hands, and other body parts. Due to the imbalance that was caused when only one side of their body was reconstructed, it became aesthetically necessary to operate on both sides in order to obtain a balance. It is also noted that patients looked younger

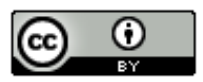

This is an open access article licensed under the terms of Creative Commons Attribution 4.0 International License (https://creativecommons.org/licenses/by/4.0/), which permits unrestricted use, distribution, and reproduction in any medium, as long as the original author is credited and the new creations are licensed under the identical terms.

For reprints contact: service@oaepublish.com

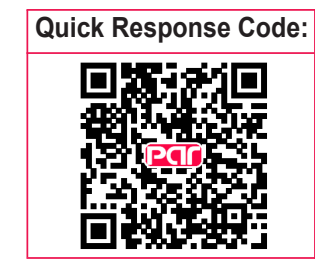


through a variety of techniques such as brow lifts, face lifts, rhinoplasty, and other procedures developed to completely change the body from subnormal to a more aesthetic appearance.

Aesthetic surgery is a growing popularity fueled by a culture that idolizes a youthful appearance ${ }^{[1]}$. Popular operations include breast augmentations, tummy tucks, and liposuction. More than 4,000 teenagers, ages 18 -year-old and younger have had breast implants and over 6,000 have undergone liposuction. Over the years, the number of plastic surgery procedures in teens has increased from 59,890 in 1997 to more than 205,119 in 2007 , nearly 4 times as many, according to Conwell ${ }^{[2]}$. Many experts claim that this increase is most likely fueled by the media through Internet and television.

Recently, there has been more of a debate over the controversy as to whether or not teens should undergo cosmetic surgery. Some argue that teenagers are simply concerned with their appearance and how their peers may view them. Undergoing plastic surgery would only suggest that happiness is "a nip and a tuck away", argues Arthur Caplan in Friedman' ${ }^{[3]}$ article. Moreover, many adolescents are not completely developed yet and have not had ample time to become accustomed to their own bodies, and thus should not be going under the knife to fix their changing insecurities. Other experts such as Schneweis ${ }^{[4]}$ claim that surgeries only offer temporary fixes and that despite a "new physical image, a fragile self-esteem may still exist". Furthermore, plastic surgery is the reconstruction of a new image, which is what those like Gilbert ${ }^{[5]}$ claim to be "against nature".

Cutis laxa refers to a rare condition that can be acquired or congenital, in which skin becomes hypoelastic causing loose, redundant skin $^{[6-7]}$. The effect of this condition causes the patient to appear decades older than their actual age ${ }^{[8-12]}$. For children suffering from this rare condition, aesthetic surgery has shown to provide a dramatic improvement in skin laxity. Aesthetic surgery to enhance the appearance of cutis laxa patients dates back to the late 1960s, where patients as young as 13-month-old benefited from such surgeries. In 1969, Dingman et al. ${ }^{[9]}$ reported a case in which a 13-monthold patient underwent the excision of large amounts of redundant skin of the neck. At just 16 months, the same patient underwent a rhytidoplasty with excision of redundant skin from the scalp, face, and neck on her right side. The British Journal of Plastic Surgery advocates for early surgical intervention in these patients, who benefit psychologically and emotionally from aesthetic surgery ${ }^{[7]}$.
In 2013, approximately $30 \%$ of American adolescents were overweight or obese. This corresponds to the $47 \%$ increase in global obesity since $1980^{[13]}$. With the rise of childhood obesity, more and more teens are undergoing weight loss surgeries such as bariatric surgery and liposuction. The controversy that surrounds childhood obesity is often fueled by critic's belief that surgery is not a necessary means for weight loss and that diet and exercise are sufficient to achieve desired results ${ }^{[14-16]}$. However, many experts argue that there is no effect of diet in the treatment of pediatric obesity and studies would suggest that dietary restriction alone is ineffective in adolescents ${ }^{[17-19]}$. Overweight and obese children lack the self-worth and social support associated with psychosocial adjustment ${ }^{[20]}$. Further research expresses the psychological effects of childhood obesity that equate to "depression, low self-esteem, and social marginalization and have decreased physical activity and lower academic scores"[17]. The Wall Street Journal (14 Sep 2017) showed that suicide is the most common death for Americans between the ages of 15 to 34. Obstructive sleep apnea (OSA) has also been associated with obesity in adolescents. The International Journal of Pediatric Otorhinolaryngology suggests that weight loss in adolescents significantly improves the effects of $\mathrm{OSA}^{[21]}$. One study consisting of patients ages 13-21 years old undergoing bariatric surgery showed a long term decrease in the prevalence of type II diabetes from $16 \%$ to only $2 \%$ after 5 plus years post-op ${ }^{[22]}$.

\section{Psycho-cybernetics}

Maltz ${ }^{[23]}$ defines self-image as the "foundation upon which your entire personality, your behavior, and even your circumstance are built". He goes on to say that one is "never too young or too old to change his selfimage and thereby start to live a new life". In recent years, this aspect of being "too young" has gained much media attention and controversy as more and more teens undergo aesthetic surgery in an effort to change their self-image. Self-image refers to the manner in which one views themselves, and is directly correlated to ones self-esteem. Maltz ${ }^{[23]}$ goes so far as to say "self-esteem is as necessary to the spirit as food is to the body". When individuals, especially teenagers and young adults, lack a level of selfconfidence, they become inherently vulnerable to rejection and psychological damage. The effect of this psychological damage can be detrimental to a teenager and their ability to function at their optimum. "When your self-image is adequate and one that you can be wholesomely proud of, you feel self-confident. You feel free to "be yourself" and to express yourself. You function at your optimum"[23]. 


\section{Beauty pays}

Hamermesh ${ }^{[24]}$ argues that those who are considered less attractive will suffer economically as compared to their colleagues who are equally as qualified, trained, and intelligent, but are considered more attractive by social means. This disadvantage equates to a loss of " $\$ 140,000$ over a lifetime compared to the earnings of an average-looking worker". In his concept referred to as "protecting the ugly", Hamermesh ${ }^{[24]}$ compares the level of disadvantages that a less attractive person experiences to that of an individual subject to discrimination based on gender, race, or disability status. Thus, he argues that the government should protect "ugly" individuals in the same ways as it has historically protected other disadvantaged groups. This protection would be for the benefit of both the "ugly", as well as the economy as a whole. He suggests correcting this net worth disparity by cash compensation from the government. He fails to mention, that cash contribution could be used to correct the very defaults that qualify for the beauty impaired (see three cases below).

The American college of obstetricians and gynecologists recently published a committee opinion based on the increasing interest of adolescents in breast and labial surgery. The committee emphasizes the necessity of physical maturity and emotional readiness when dealing with adolescent patients, as well as "education and reassurance regarding normal variation in anatomy, growth, and development"[25]. The necessity of these procedures is often questioned and highly controversial, as nonsurgical alternatives appear to be much more practical and less invasive for adolescents. Dr. Abbey B. Berenson believes that most women will likely never notice the variance in appearance of external genitals, and those that do feel insecure about their genitalia should be well informed and counseled on this natural variance ${ }^{[26]}$. This normal variation among women includes size, shape, and appearance of external genitalia including the labia minora. The committee argues that asymmetry is seen as a "normal variant" and "despite increased awareness and focus on the appearance of the external genitalia, no consensus on the definition of labial hypertrophy or criteria for surgical intervention

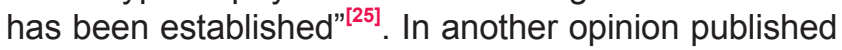
by The American College of Obstetricians and Gynecologists, the committee argues that patients who are already anxious and insecure regarding their genital appearance or sexual function may actually be "further traumatized" by such procedures that lack supporting data on safety and efficacy. The committee states it is "deceptive" of physicians to give the impression that such procedures are accepted and routine surgical practices ${ }^{[27]}$. They seem to be unaware of the extensive literature that discusses standards of normality ${ }^{[28-31]}$ and other opinions based on actual clinical experience with patients and their families.

Countless evidence provided by Michael Olding in Friedman's ${ }^{[3]}$ article seems to show that plastic surgery can actually limit psychological consequences and physiological consequences. For example, otoplasty helps remove what others coin "dumbo ears", which in effect removes the bullying stimulus. Other operations, such as breast reduction, gynecomastia and macromastia, can actually help with physiological consequences as extremely large breasts can cause back and shoulder pain. Through undergoing cosmetic surgery, procedures can alleviate significant psychological strain and improve self-esteem. Moreover, it is unfair that teenagers should be excluded from plastic surgery simply due to their age, especially when some parts of the body such as the nose, reach complete maturation in the teenage years. Furthermore, plastic surgery is not harming anyone else and only helps boost self-confidence of the patient, and thus should be allowed for anyone, no matter what age, seeking out aesthetic surgery.

\section{CASE REPORT}

All of our patients have been operated in our outpatient surgery facility where they were discharged to go home or to a hotel that night. All of our previous patients have been treated with valium and ketamine sedation exclusively. We have performed more than 30,000 aesthetic operations since 1978 to the present day; all have been performed with valium and ketamine sedation, discharged same day. In 40 years, there have been about 100 patients under 18 years of age none experienced complications, deep vein thrombosis or mortality ever. We present 3 cases in detail of teenage cosmetic surgery to illustrate that earlier is better.

\section{Patient 1}

Our first patient was a 15-year-old girl who had a peculiar habitus, perhaps Ehlers-Danlos syndrome where she had very lax skin, a hypoplastic chin and a large nose. She was depressed because she looked far older than her older sister and even her mother. They were unable to find anyone in her native England homeland to consider doing aesthetic surgery for a 15 -year-old girl. Thus, she was an outcast at school, was ridiculed and had a terrible self-image. The patient had even contemplated suicide.

As seen in the Figure 1, we did a face-lift, brow-lift, rhinoplasty, and chin augmentation for this girl as an 
outpatient. She is now back in school, has been living a normal life, is engaged, and will soon be married. She and her family were delighted with the results and she is now a normal, happy person.

\section{Patient 2}

Our second patient [Figure 2] was a 12-year-old grossly overweight girl, at an astonishing 230 pounds. She had tried every method of dieting possible, but nothing had worked ${ }^{[32]}$. Her father called in asking if we would consider doing liposuction for a 12-year-old girl. Our initial impulse was to decline, but we decided
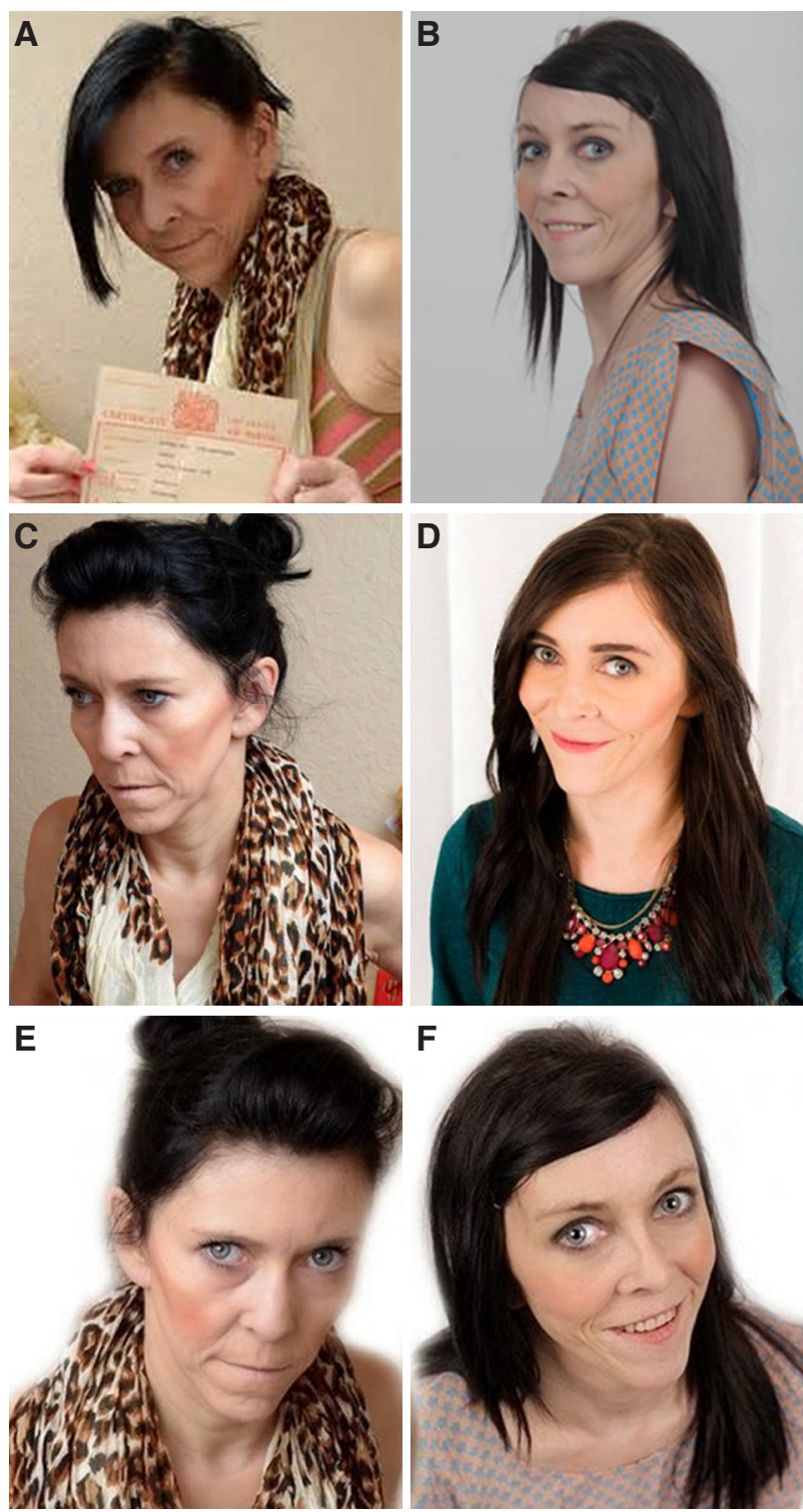

Figure 1: A: Patient 1 at age 15 holding her birth certificate; B: patient 1 at 6 months later, post brow lift, face lift, rhinoplasty, autologous fat transplantation to lips ( $3 \mathrm{~mL}$ upper lip, $1 \mathrm{~mL}$ lower lip) and cheeks ( $3 \mathrm{~mL}$ each), and chin augmentation; C: side view of patient 1 prior to surgical procedures; D: side view of patient 1 at 6 months post-op; E: profile view of patient 1 prior to any procedures; F: profile view of patient 1 at 6 months post all procedures to meet with her family. In the process of discussing different liposuction methods, the family explained that their daughter was unable to exercise because after an attempt to run or do strenuous calisthenics, she would become plethoric and dyspnic. She confided that she had no friends and was bullied for being overweight.

She mentioned how she had gone to a birthday party in which the whole class was invited. Later that night, the parents of the birthday child called for her mother to come take her home, but she had noticed that all the other girls had sleeping bags hidden. She felt that they sent her home because they did not like her
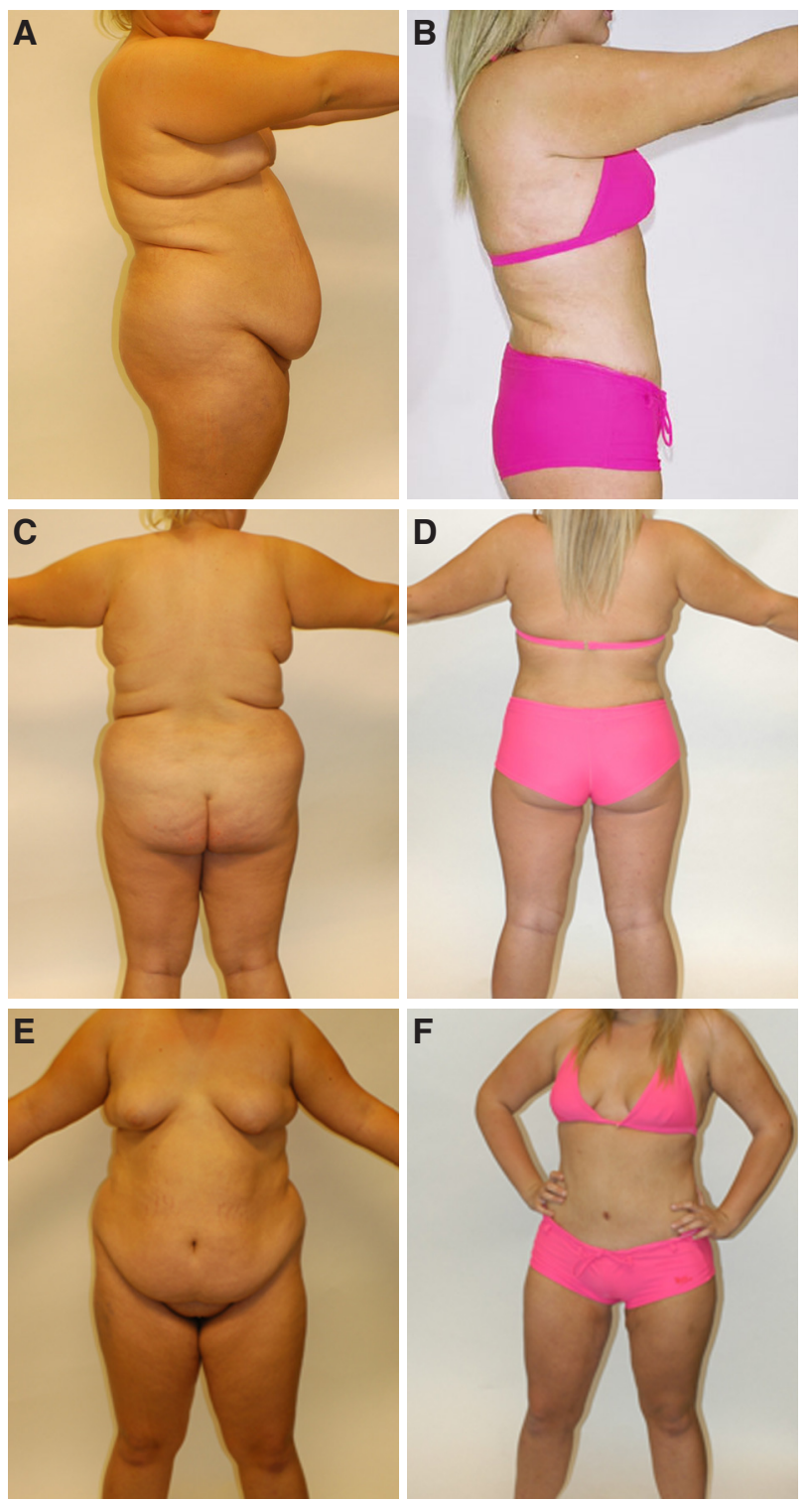

Figure 2: A: Patient 2 at 12-year-old and 230 pounds; B: patient 2 at 5 months post liposuction (3 times), abdominalplasty, brachioplasty, and medial thigh lift. Total weight loss of 58 pounds and weight of 185 pounds; C: rear view of patient 2 at 219 pounds, prior to all surgical procedures; D: rear view of patient 2 at 5 months postop at a weight of 160 pounds; $E$ : front view of patient 2 prior to any surgical intervention; $\mathrm{F}$ : front view of patient 2 at 5 months post-op 
in company. As a result, she was quite desperate to have something done and had even mentioned the thought of suicide. The patient discussed her hope of her father seeing her in a nice dress before he died of bladder cancer.

To help her achieve her dreams and eliminate humiliation, we did liposuction with 2 units of autologous blood and removed $15 \mathrm{~L}$ (about 38 pounds) of subcutaneous fat (including $8 \mathrm{~L}$ of infiltration), followed by 2 other liposuction procedures after waiting for complete healing in 6 weeks. Additionally, we did a breast augmentation, abdominoplasty, brachioplasty, and a thigh lift on the patient.

Figure 2A shows the patient at just 12-year-old and 230 pounds, prior to any surgical intervention. Her menarche had begun at age ten so physiologically, she was mature.

Figure 2B was taken just 5 months after all procedures and an astonishing 58-pound weight loss. Since then, the patient continued her weight loss journey and weighed in at 152 pounds after a year. Her life has become normalized, as she is enrolling in college as a nursing student and has recently gotten married.

\section{Patient 3}

Case 3 [Figure 3] is a 14-year-old boy who was overweight. He had very few friends and was an introvert because of low self-esteem, especially pertaining to his big legs, gynecomastia, and overweight body habitus. His father brought him in to evaluate his lower extremities, as he was concerned the legs may become a chronic lymph edema or permanent deformity.

Under valium and ketamine sedation, we performed liposuction to his legs, pelvis, abdomen, and chest. After returning back to school, he obtained more friends, became athletic, a straight A student, and took extra elective courses so he could graduate from high school with a grade point average above a 4.0. He has recently been accepted to a top university of his choice.

\section{DISCUSSION}

It is often stated by people like caplain in Friedman's ${ }^{[3]}$ article that teenagers are too young to make a decision about their appearance permanently. It perhaps would be better to wait until they are fully mature, at ages 21 through 25. Moreover, some believe that surgery is risky for young people. However, there is no evidence for that rumor, as we do not hesitate to operate on infants with cleft lips at merely 10 weeks of age, 10 pounds of weight, and hemoglobin of 10 grams. Otoplasties are usually performed before children go to school to prevent them from being ridiculed for their entire life ${ }^{[3]}$.
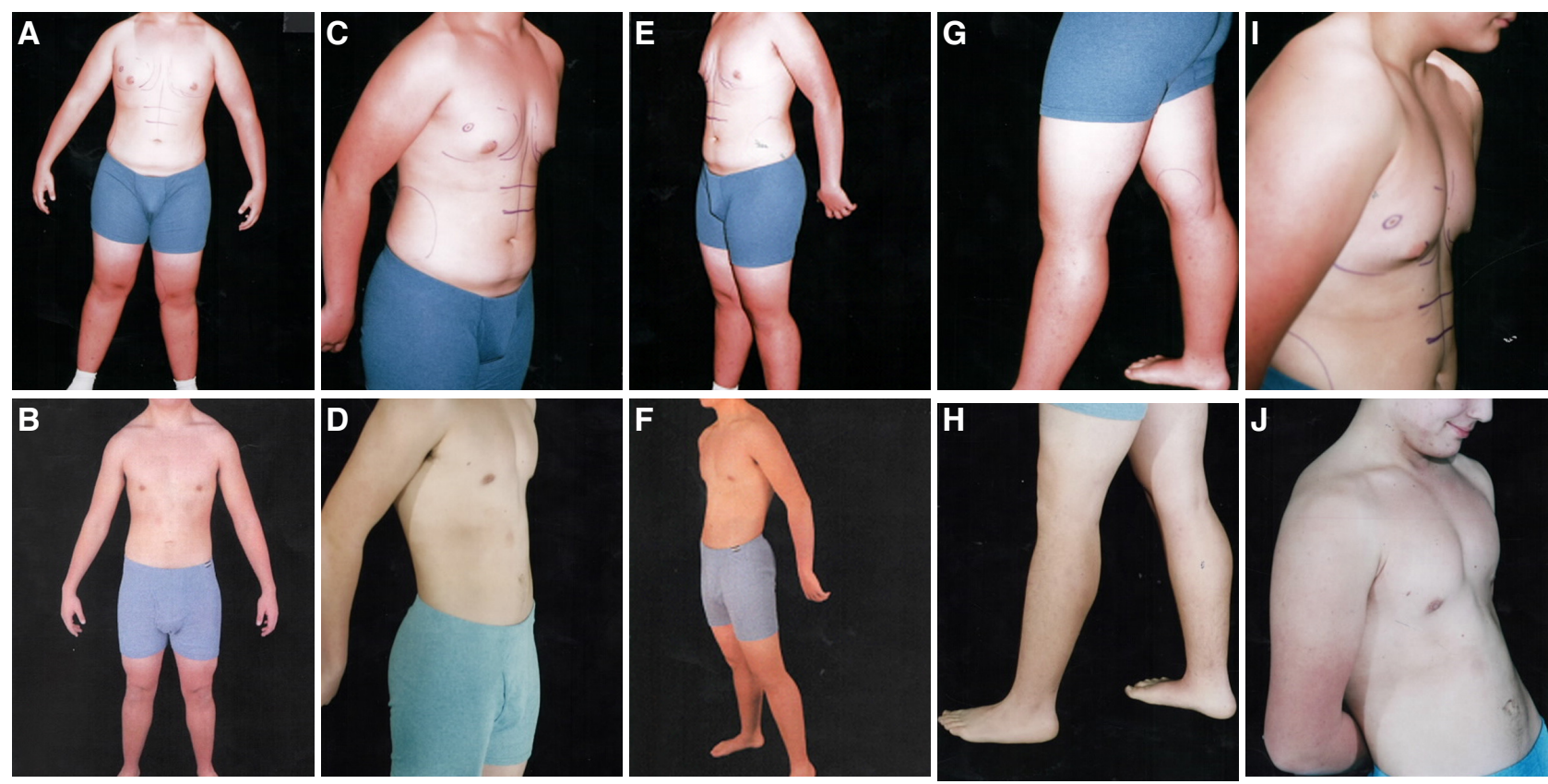

Figure 3: A: Patient 3 at 14-year-old and 220 pounds; B: patient 3 one year later, post liposuction to his chest, abdomen, flanks, knees, calves, and thighs; C: patient 3 prior to any surgical intervention; D: patient 3 one year post-op; E: side view of patient 3 prior to surgical procedures; F: side view of patient 3 one year post-op; G: legs and calves of patient 3 prior to any surgical procedures; H: legs and calves of patient 3 one year post-op; I: side view of chest and abdomen of patient 3 prior to all surgical procedures; J: side view of chest and abdomen of patient 3 one year post-op 
Lee et al. ${ }^{[33]}$ studied 3,534 adolescents. Their findings were that, "Adolescents involved in bullying, in any role, were significantly more interested in cosmetic surgery that uninvolved adolescents." Desire for cosmetic surgery was highest in girls. Being victimized by peers resulted in poor psychological function.

In a review of the literature, they found that $50 \%$ of adults seeking cosmetic surgery report a history of teasing or bullying mostly during adolescence ${ }^{[34-37]}$. There is now ample evidence that peer victimization is a childhood trauma that negatively affects psychological function both concurrently and longitudinally ${ }^{[38-42]}$.

There is no reason why these children should be condemned to suffer for so many years as they are often socially rejected and are treated negatively by their peers. These children undergo psychological damage through being bullied or teased about their appearance. Furthermore, the younger the individual is, the healthier they generally are, and the more likely they are able to respond favorably to a surgical procedure $^{[3-5,23,24,32]}$. The safety of procedures like sequential (serial) liposuction has been extensively studied and there is much literature that supports this method of large-scale liposuction ${ }^{[43-46]}$. As seen in patient number 2, the safest method of removing large amounts of fat is to remove the fat in serial subsequent episodes $^{[26]}$. The effect of this level of weight loss on a young person is not only psychologically and emotionally beneficial, but also a key step into a healthier lifestyle, a lifestyle that is not subject to health factors like Type II diabetes, hypertension, etc. ${ }^{[26]}$

The protocol of using ketamine and valium sedation is "found to be effective, reliable, and reproducible, and the experiences of the patient and plastic surgeon

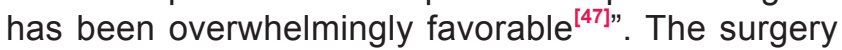
should be performed after complete consolation with their parents at any age ${ }^{[48-50]}$. The guidelines are: (1) objective evidence of a correctible defect by the surgeon and staff; (2) the patient actively seeks correction; (3) both parents agree. Thus aesthetic plastic surgery may make a substantial difference in a child's life.

\section{DECLARATIONS}

\section{Acknowledgments}

I would also like to thank Mark Salisbury, Eugene Gonzales, Angelica Hesles and the rest of the staff at Personique Surgery Center.

\section{Authors' contributions}

Chief Surgeon for each case, collected photos, wrote the case report: R.A. Ersek

Editorial review and offered clinical advice pertaining to literature: D. Derrick, L. Crawford, J. Sheridan, R. Buckspan

Researched related literature and corrected article grammer: A. Delgado, S. Gualy, D. Vo, M. Salisbury

\section{Financial support and sponsorship} None.

\section{Conflicts of interest}

There are no conflicts of interest.

\section{Patient consent}

In this study, all patients give their consent.

\section{Ethics approval \\ Not applicable.}

\section{REFERENCES}

1. Bhattacharya S. Jacques Joseph: father of modern aesthetic surgery. Indian J Plast Surg 2008;41:S3-8.

2. Conwell V. "Better health: more teens put best face, body forward: plastic surgery can improve image and self-confidence." Available from: http://search.proquest.com.dbgw.lis.curtin.edu.au/docview/337 527750 ? accountid $=10382$. [Last accessed on 18 Oct 2017]

3. Friedman J. Cosmetic Surgery. CQ Researcher 2005;15:317-44.

4. Schneweis E. Cosmetic surgery may be harmful to teenagers. In: Auriana Ojeda, editors. Body Image. New York: Greenhaven Press; 2003.

5. Gilbert S. Children's bodies, parents' choices. Hastings Cent Rep 2009;39:14-5.

6. Banks ND, Redett RJ, Mofid MZ, Manson PN. Cutis laxa: clinical experience and outcomes. Plast Reconstr Surg 2003;111:2434-42; discussion 2443-4.

7. Beighton P, Bull JC, Edgerton MT. Plastic surgery in cutis laxa. $B r J$ Plast Surg 1970;23:285-90.

8. Thomas WO, Moses MH, Craver RD, Galen WK. Congenital cutis laxa: a case report and review of loose skin syndromes. Ann Plast Surg 1993;30:252-6.

9. Dingman RO, Grabb WC, Oneal RM. Cutis laxa congenita-generalized elastosis. Plast Reconstr Surg 1969;44:431-5.

10. Berk DR, Bentley DD, Bayliss SJ, Lind A, Urban Z. Cutis laxa: a review. J Am Acad Dermatol 2012;66:842.e1-17.

11. Kaplan EN, Henjyoji EY. Pseudoxanthoma elasticum: a dermal elastosis with surgical implications. Plast Reconstr Surg 1976;58:595-600.

12. Broughton G 2nd, Janis JE, Attinger CE. A brief history of wound care. Plast Reconstr Surg 2006;117:S6-11.

13. Mingrone G. Pros and cons of bariatric surgery in adolescents. Lancet Diabetes Endocrinol 2017;5:152-4.

14. Ersek RA. Too Young For Lipo? Available from: http://people.com/ archive/too-young-for-lipo-vol-66-no-20/. [Last accessed on 18 Oct 2017]

15. Ersek RA. Pre-teen procedures: How young is too young for lipo and a tummy tuck? This surgeon claims he had both science and circumstance on his side before operating - and he'd do it again. Available from: http://aestheticchannel.modernmedicine.com/ cosmetic-surgery-times/news/clinical/cosmetic-surgery/pre-teen- 
procedures-how-young-too-young-lipo-a $2 \mathrm{id}=\& \mathrm{sk}=\&$ date $=\& \% 0 \mathrm{~A} \% 0$ $9 \% 09 \% 09 \&$ pageID $=4$. [Last accessed on 18 Oct 2017]

16. Ersek RA. Is 12 too young for lipo? Available from: http://connection. ebscohost.com/c/articles/22986125/too-young-lipo. [Last accessed on 18 Oct 2017]

17. Hsia DS, Fallon SC, Brandt ML. Adolescent bariatric surgery. Arch Pediatr Adolesc Med 2012;166:757-66.

18. Mark AL. Dietary therapy for obesity: an emperor with no clothes. Hypertension 2008;51:1426-34; discussion 1434.

19. Mark AL. Dietary therapy for obesity is a failure and pharmacotherapy is the future: a point of view. Clin Exp Pharmacol Physiol 2006;33:857-62.

20. Reiter-Purtill J, Gowey MA, Austin H, Smith KC, Rofey DL, Jenkins TM, Garland BH, Zeller MH; TeenView Study Group and in cooperation with Teen-LABS Consortium. Peer victimization in adolescents with severe obesity: the roles of self-worth and social support in associations with psychosocial adjustment. $J$ Pediatr Psychol 2017;42:272-82.

21. Andersen IG, Holm JC, Homøe P. Obstructive sleep apnea in obese children and adolescents, treatment methods and outcome of treatment - a systematic review. Int J Pediatr Otorhinolaryngol 2016;87:190-7.

22. Inge TH, Jenkins TM, Xanthakos SA, Dixon JB, Daniels SR, Zeller $\mathrm{MH}$, Helmrath MA. Long-term outcomes of bariatric surgery in adolescents with severe obesity (FABS-5+): a prospective follow-up analysis. Lancet Diabetes Endocrinol 2017;5:165-73.

23. Maltz M. Psycho-Cybernetics: updated and expanded. New York: Perigee, an imprint of Penguin Random House LLC; 2015.

24. Hamermesh DS. Beauty pays: why attractive people are more successful. NJ: Princeton University Press; 2011.

25. ACOG Committee Opinion. Breast and labial surgery in adolescents. Available from: https:/www.acog.org/Resources-And-Publications/ Committee-Opinions/Committee-on-Adolescent-Health-Care/Breastand-Labial-Surgery-in-Adolescents. [Last accessed on 18 Oct 2017]

26. ACOG Committee Opinion. ACOG advises against cosmetic vaginal procedures due to lack of safety and efficacy data. Available from: https://www.acog.org/About-ACOG/News-Room/ News-Releases/2007/ACOG-Advises-Against-Cosmetic-VaginalProcedures. [Last accessed on 18 Oct 2017]

27. ACOG Committee Opinion. Vaginal "rejuvenation" and cosmetic vaginal procedures. Available from: https://www.acog.org/ResourcesAnd-Publications/Committee-Opinions/Committee-on-GynecologicPractice/Vaginal-Rejuvenation-and-Cosmetic-Vaginal-Procedures. [Last accessed on 18 Oct 2017]

28. Alter GJ. A new technique for aesthetic labia minora reduction. Ann Plast Surg 1998;40:287-90.

29. Girling VR, Salisbury M, Ersek RA. Vaginal labioplasty. Plast Reconstr Surg 2005;115:1792-3.

30. Felicio Yde A. Labial surgery. Aesthet Surg J 2007;27:322-8.

31. Chang P, Salisbury MA, Narsete T, Buckspan R, Derrick D, Ersek RA. Vaginal labiaplasty: defense of the simple "clip and snip" and a new classification system. Aesthetic Plast Surg 2013;37:887-91.

32. Scott K, Ersek RA. Fat is not funny. Austin: Med Web Publishing Print; 2007.

33. Lee K, Guy A, Dale J, Wolke D. Adolescent desire for cosmetic surgery: associations with bullying and psychological functioning. Plast Reconstr Surg 2017;139:1109-18.

34. Markey CN, Markey PM. Correlates of young women's interest in obtaining cosmetic surgery. Sex Roles 2009;61:158-66.

35. Javo IM, Sørlie T. Psychosocial characteristics of young Norwegian women interested in liposuction, breast augmentation, rhinoplasty, and abdominoplasty: a population-based study. Plast Reconstr Surg 2010;125:1536-43.

36. Jackson AC, Dowling NA, Honigman RJ, Francis KL, Kalus AM The experience of teasing in elective cosmetic surgery patients. Behav Med 2012;38:129-37.

37. Von Soest T, Kvalem IL, Skolleborg KC, Roald HE. Psychosocia factors predicting the motivation to undergo cosmetic surgery. Plast Reconstr Surg 2006;117:51-62; discussion 63-4

38. Stapinski LA, Bowes L, Wolke D, Pearson RM, Mahedy L, Button KS, Lewis G, Araya R. Peer victimization during adolescence and risk for anxiety disorders in adulthood: a prospective cohort study. Depress Anxiety 2014;31:574-82.

39. Wolke D, Lereya ST, Fisher HL, Lewis G, Zammit S. Bullying in elementary school and psychotic experiences at 18 years: a longitudinal, population-based cohort study. Psychol Med 2014;44:2199-211.

40. Lereya ST, Copeland WE, Costello EJ, Wolke D. Adult mental health consequences of peer bullying and maltreatment in childhood: two cohorts in two countries. Lancet Psychiatry 2015;2:524-31.

41. Lereya ST, Copeland WE, Zammit S, Wolke D. Bully/victims: a longitudinal, population-based cohort study of their mental health. Eur Child Adolesc Psychiatry 2015;24:1461-71.

42. Takizawa R, Maughan B, Arseneault L. Adult health outcomes of childhood bullying victimization: evidence from a five-decade longitudinal British birth cohort. Am J Psychiatry 2014;171:777-84

43. Narsete T, Narsete M, Buckspan R, Ersek R. Large-volume liposuction and prevention of type 2 diabetes: a preliminary report. Aesthetic Plast Surg 2012;36:438-42.

44. Girling RG 5th, Salisbury MA, Ersek RA. Sequential (serial) suction Clin Plast Surg 2006;33:75-7.

45. Ersek RA. Autologous blood transfusion in plastic surgery. Plast Reconstr Surg 1990;85:828-9.

46. Ersek RA, Salisbury M. Mega lipo: how large volume lipsuctions may improvem obesity, hypertension, fertility, diabetes (Type II), and longevity. NY: Mww Publishing Inc; 2004.

47. Quttainah A, Carlsen L, Voice S, Taylor J. Ketamine-diazepam protocol for intravenous sedation: The cosmetic surgery hospital experience. Can J Plast Surg 2004;12:141-3.

48. Ersek RA. Dissociative anesthesia for safety's sake: ketamine and diazepam - a 35-year personal experience. Plast Reconstr Surg 2004;113:1955-9.

49. Viggiano DA, Gill RB, Derrick D, Salisbury MA, Buckspan R, Pittman-Waller VA, Doshi PV, Girling RGW, Narsete T, Ersek RA. VeVaKet safer sedation: no gases. How VeVaKet (versed or valium and ketamine) can eliminate the dangerous complication of general anesthesia gases (GAG). USA: FileMaker, Inc; 2011.

50. Ersek RA. General anesthesia gases are a common denominator in cases of thromboembolism. Aesthet Surg J 2009;29:340-1. 